\title{
Typical Case Study on Zhejiang Modern Service Industry Clusters, Haining Warp Knitting Industry and Producer Services Cluster Park
}

\author{
Chun-Xiang LIU ${ }^{1, a,{ }^{*}, \text { Li-Yuan ZHU }}{ }^{1, b}$ \\ 'Zhejiang Wanli University, Ningbo City, Zhejiang Province, China \\ acxafa@126.com, 'bLYQS3821@163.com \\ ${ }^{*}$ Corresponding author
}

\begin{abstract}
Keywords: Modern Service Industry Clusters, industrial division, Haining Warp Knitting Industry, development priorities.
\end{abstract}

\begin{abstract}
This article explains and demonstrates current situation of Haining Warp Knitting Industry and Producer Services Cluster Park, which is the most typical one of Zhejiang Modern Service Industry Clusters. Base on the description of the development orientation and goals of that cluster park, this article has analyzed its development priorities and then concluded its main lessons. Those experiences and lessons can provide a good reference to the other service industry clusters.
\end{abstract}

\section{General about Zhejiang Modern Service Industry Clusters}

The rapid development of the service industry in Zhejiang has laid a solid foundation for the centralization of the modern service industry. 9 of 14 industrial clusters mentioned in The General Development Plan of Zhejiang Industrial Clusters involve the modern service industry. In 2010, Zhejiang Provincial Development and Reform Commission issued Opinions about Establishing Demonstrative Modern Service Industry Clusters in Zhejiang, and granted the first group of 40 demonstrative modern service industry clusters of Zhejiang. It explicitly specified that: Zhejiang would establish nearly 100 modern service industry clusters with an emphasis on 9 categories including logistics parks, headquarters bases, incubators and creativity industry parks. It was aimed at guiding the service industry to transform from "scattered" to "centralized".

In April 2012, Zhejiang announced the second group of 35 modern service industry clusters. In September 2013, it announced the third group of 25 modern service industry clusters. So far, Zhejiang modern service industry clusters have attained initial achievements. According to statistics, by the end of June 2013, 75 industrial clusters (the 1st and 2nd group) had finished 30 investment projects, achieved the operating revenue of 951.77 billion Yuan, and attracted 82000 enterprises to settle in and 452000 persons to work there. As Zhejiang modern service industry clusters are stably promoted, it will solve problems of "industrial isomorphism", "repeated construction", "excessive competition", efficiency loss and congestion of production factors existing in Zhejiang service industry. Moreover, it is conducive to the sustainable development of Zhejiang modern service industry.

This paper will select Haining warp knitting industry and producer services cluster park as a typical case to analyze its current development, sum up its experience and provide effective references to other service industry clusters.

\section{Development Orientation and Goals of Haining Warp Knitting Industry and Producer Services Cluster Park}

Haining warp knitting service cluster belongs to the first group of demonstrative modern service industry clusters of Zhejiang. It is based on the thought of advancing the warp knitting industry, developing Maqiao and constructing the new southern district. It plans to extend the value chain, integrate resources, optimize industrial division, greatly develop the producer services industry and mildly centralize the consumer services industry. As Maqiao is constructed to be the key producer services industry base and the regional headquarters economy cluster of Haining, it will create new urban spaces 
covering research \& test, logistics \& exhibition, specialized markets, headquarters economy, commercial housing and supporting services.

In terms of its development orientation, it will be developed to be the integrated service platform of Maqiao warp knitting industry, an important part of the new southern district of Haining, the headquarters base based on its specialized industry in Zhejiang, and the key supporting platform for the consumer services industry of Maqiao Community.

In terms of its development goals: by 2015 , it will basically complete the infrastructure construction of the park, have significant projects signed, roughly shape the cluster park and reasonably arrange inner space. In addition, it will form a complete set of investment attraction modes characterized by local features and modern features. A group of significant projects will be built and put into use, including office buildings for the logistics base, buildings for the headquarters economy zone, apartments for talents and star-rated hotels. The added value of the service industry will reach 200 million Yuan, and more than 2000 persons will work there. By 2020, the complete infrastructure system will be generally constructed. Significant follow-up projects will be started, including high star-rated hotels, research \& test building, cultural center, high-grade commercial buildings and creativity industry building. The added value of the service industry of the park will reach 500 million Yuan, and more than 4000 persons will work there.

\section{Development Priorities of Haining Warp Knitting Industry and Producer Services Cluster Park}

\section{Focus on Constructing Seven Function Areas}

(1) Warp Knitting Industry Promotion Center (Warp Knitting Building). It has been constructed and put into operation. (2) Test and Research Function Area. Based on Zhongtian Test, Technical Center and Warp Knitting Research Institute, according to the development of test and research business, a building and related supporting houses will be constructed on the land plot of $50 \mathrm{mu}$ (about 3.33 hectares) (to the south of Jingdu Erlu, the north of Jingdu Silu, the west of Jingdu Sanlu and the east of Jingdu Wulu). It will provide research and technical support for the development of the warp knitting headquarters. (3) Headquarters Economy and Office Building Area. It occupies an area of $220 \mathrm{mu}$ (about 14.67 hectares) and is comprised of headquarters compounds with gardens and business offices characterized by intelligent, low-density and ecological. (4) Entrepreneurship Center (incubator). It occupies an area of $130 \mathrm{mu}$ (about 8.67 hectares). A group of standard factory buildings, shared spaces and supporting facilities are planned to be constructed for incubating SMEs. (5) Hotels and integrated supporting area. It occupies an area of $35 \mathrm{mu}$ (about 2.33 hectares). It will incorporate a high-grade hotel (five-star), apartments for talents (Hexie Residential Quarters), integrated supporting service area, integrated supporting consumer services area and business area. (6) Logistics Trading Area. It occupies an area of $200 \mathrm{mu}$ (about 13.33 hectares). It will include logistics industry, administration and information trading, supporting logistics area, transportation (parking space) area, warehousing \& distribution area, water transport area and auto service area. (7) Creativity Industry Area. It occupies an area of $80 \mathrm{mu}$ (about 5.33 hectares). A group of creative, unique and artistic buildings will be constructed for satisfying industrial design, digital entertainment and software service industries' demands.

\section{Focus on Developing Eight Industry Categories}

(1) Modern logistics industry. An integrated logistics base will be constructed, which, based on the warp knitting park, is aimed at serving Haining and the Yangtze River Delta. It combines less-than-truck-load transport, warehousing and distribution. Medium- and large-sized enterprises are encouraged to separate their logistics link and also develop socialized and specialized third-party logistics business. (2) Specialized market and exhibition industry. Relying on China Warp Knitting Headquarters Market, it will set up a centralized warp knitting products exhibition center in the central area, accompanied with business offices at two sides for marketing, display and office work. (3) Product test and standardization service industry. The test and standardization service industry will be developed to be

leading among Maqiao knowledge-based service industries and also grow to be a new growth point of regional economy. (4) Research service and consultancy industry. It will enhance connection and cooperation with famous domestic and foreign institutions and experts. Moreover, it will organize an 
annual warp knitting industry development forum to advance the development of the warp knitting industry. (5) Information service industry. It will integrate seven network resources and construct "China Warp Knitting Website" which will be constructed to be the largest warp knitting industry information service platform in China and even in the world as well as a specialized e-business platform. (6) Headquarters economy. It will actively attract warp knitting enterprises and related textiles/garment enterprises to settle their headquarters, research centers and sales centers in. (7) Integrated supporting service industry. It will gradually attract financial institutions such as trust, securities, insurance and venture investment to settle in, and develop the commercial service industry such as finance, law, job-hunting and advertising, which advances the supporting consumer services industry. (8) Creativity industry. It focuses on developing fashion design, advertising design, arts and crafts making, industrial design, internet media, fashion art, environmental art, animation and other creativity industries.

\section{Current Development of Haining Warp Knitting Industry and Producer Services Cluster Park}

By the end of 2012, this cluster park had constructed ten innovative service platforms covering modern logistics, technological research, technology consultancy, product test, modern exhibition and specialized market, financial guaranty, etc. At present, it is constructing seven areas including the warp knitting industry promotion center, the entrepreneurship center and the creativity industry area, and also developing eight industries involving modern logistics, finance, headquarters economy and technological research. 197 enterprises have settled in this cluster park. The completed investments have accumulated to 1 billion Yuan with the investment intensity up to 4.327 million Yuan/Mu. The operating revenue per unit and the tax income per unit have reached 64.2 million Yuan/Mu and 1.1298 million Yuan/Mu respectively. The producer services industry in this park mainly includes followings:

Technological research and test services. The park has established the technology center and Zhejiang Haining Warp Knitting Productivity Promotion Center which are mainly engaged in the research, development and trial production of warp knitting products. Moreover, in cooperation with some universities and research institutions specialized in textile industry, including Donghua University, Tianjin Polytechnic University and Jiangnan University, they jointly solve technical problems for enterprises. Through trilateral cooperation, they have set up "Industry-Purpose Warp Knitting Products Research and Development Center" and "Garment-Purpose Warp Knitting Products Research and Development Center". As resources are shared, they attract high-quality talents, provide perfect laboratory equipment and conditions for talents and carry out development and technological innovation of warp knitting products.

E-business and information service. The information center is responsible for informative services for the park and the whole society. By connecting the network of enterprises in the park, it can post technological questions and answers on the Internet. Seven websites have been constructed, including "China Warp Knitting Information Website", "China Warp Knitting Products Website", "China Industry-Purpose Fabrics Website”, "Zhejiang Haining Warp Knitting Industrial Park Website", "China Warp Knitting Headquarters Market Website”, "Zhejiang Online Technology Market_Warp Knitting Market" and "Zhejiang Haining Warp Knitting Industrial Park-Standard Information Integrated Service Platform". To provide better services for enterprises and construct specialized and authoritative information publishing channels, the information center is integrating network resources and these websites will be integrated to be one website with twelve channels.

Exhibition and specialized market. The investigation \& exhibition department and the external liaison \& cooperation department in the park have organized enterprises to participate in Shanghai Garment Fabric Exhibition, IFAI Expo (USA), JFW International Fashion Fair (Japan), REKLAMA (Russia) as well as other specialized exhibitions in Singapore and Turkey for years. Currently, more than 130 enterprises have settled in. By the end of 2010, traders had notched up 3500 person times and the turnover had exceeded 400 million Yuan. Based on this market, the park successfully held the 1 st China. Maqiao Warp Knitting Trade Fair in 2010.

Headquarters building. China Warp Knitting Headquarters Building is aimed at constructing an integrated service platform for the park, including producer services of technological innovation (R\&D, 
consultancy, information), modern exhibition and specialized market, commerce (accounting, law, brand, secretary, talents), finance and culture, which is helpful for creating headquarters economy.

Financial guarantee service. To help SMEs overcome difficulties in financing and guarantee, the park has taken measures to solve their fund problems such as bank-enterprise meetings and financial service studios. Moreover, it has registered and established Haining Jiafeng Guarantee Co., Ltd. mainly working on financing guarantee, financing agency and industrial investment. By the end of 2010, Jiafeng Guarantee had made 488 deals and provided financing guarantee of 668 million Yuan for more than 200 SMEs, accounting for more than 50\% market shares in Haining. It ranked top 5 among 60 guarantee institutions in Jiaxing. As credit cooperatives, the national tax authority and ICBC have settled in the park, it is convenient for enterprises to deal with financial business.

Agency and consultancy services. Since enterprises are confronted with shortage of financial employees and lack of financial management in recent years, the park has established Haining Warp Knitting Park Zhengda Accounting \& Tax Services Co., Ltd. which provides tax consultancy, adviser, bookkeeping and other related services. At present, it has rendered adviser services for 20 companies and bookkeeping services for 200 companies. Moreover, law firms, trademark \& patent firms, and certification consultancy institutions will gradually be settled in the park. They will provide consultancy services on law, brand trademark and certifications for SMEs.

Talents and labor services. The park established Haining Warp Knitting Park Employment Agency Co., Ltd. in 2005. By posting jobs and recruitment information, it has built a bridge between enterprises and job seekers and successfully introduced more than 6000 job seekers. After the Spring Festive last year and this year, it organized a job fair especially for the warp knitting park to help enterprises recruit workers. In addition, the park also organizes enterprises to recruit talents from universities and colleges in Shanghai, Wuhan, Wuxi, Hangzhou, Shenyang and Chengdu, which improves the quality of their employees.

Training and education services. The park has established Haining China Warp Knitting Vocational School and Haining Warp Knitting Technique Center which mainly provide correspondence courses on warp knitting and accounting as well as short-term trainings on warp knitting, machine operation and oral English. It has been an excellent off-campus practice base of Zhejiang. The technique center mainly trains high-end technicians for enterprises and conducts specialized trainings jointly with Zhejiang Sci-Tech University and Jiangnan University.

Corporate culture service. Since its establishment, Haining Chengying Advertising Co., Ltd. is specialized in serving enterprises in the park. It renders services of outdoor advertising, billboard advertising, single pillar advertising, triangle advertising, product brochures and window advertising in the park. It effectively improves brand awareness and brand image of enterprises inside the park.

Modern logistics and other social services. The park has established Haining Warp Knitting Park Zhengrong Logistics Co., Ltd., Haining Warp Knitting Park Ziwei Travel Agency Co., Ltd., Haining Meilin Bay Ecological Park Agritourism Co., Ltd., Chengnan Construction \& Development Co., Ltd., Haining Maqiao Hualian Shopping Center Co., Ltd., Haining Hexie Residential Quarters Property Management Co., Ltd., Haining Warp Knitting Park Wanzhong Xuanyi Property Management Co., Ltd. and other social service entities. They not only meet the demands of the producer services industry, but also satisfy corporate demands.

\section{Main Lessons from Haining Warp Knitting Industry \& Producer Services Cluster Park}

Focus on the warp knitting industry chain and speed up the development of the producer services industry. The development trend of global industrial clusters at present is to create complete industrial chains. So far, Maqiao warp knitting cluster, which mainly highlights the production link, is an incomplete cluster industry with little integrated competitiveness. Both upstream links of logistics, marketing and exhibition and downstream links of research, information service and test have to be further developed and perfected. The arrangement of projects in the service industry cluster park must be conducive to upstream and downstream links, to the division of labor in the production link, and to the improvement of efficiency. Thus, it can further promote the development of Maqiao warp knitting industry cluster and improve its competitiveness and position in both domestic and foreign markets. 
Highlight the capability of innovating warp knitting products and create an advanced manufacturing industry innovation platform. After years' development, warp knitting companies inside the park have greatly improved production equipment. However, compared to internationally leading warp knitting companies, they lack innovative talents, innovative network and innovative platform. Moreover, they are weak in the capability of independently developing new products and their products are less competitive. Therefore, the established service industry cluster park must highlight the innovation function, focus on the construction of an innovation network platform and a quality test platform, attract more innovative talents, optimize the cooperative relationships between enterprises, create an advanced innovation platform, pool efforts in solving some common technical problems, and realize product upgrading and diversification. It shall lay a solid foundation for enterprises in the park to compete in internationally medium- and high-end markets.

Promote warp knitting companies to separately develop the service industry, reduce operating costs and improve efficiency. At present, enterprises inside the park gain little supporting services for cooperation between each other and have high operating costs. The established service industry cluster park must be aimed at improving the operating efficiency of enterprises inside. As a lot of public service platforms covering logistics, $R \& D$, test, finance, information, exhibition, sales, culture and capital are constructed, enterprises inside the park may receive professional, high-quality and authoritative services nearby with lower costs. Relying on these platforms, enterprises can strip services with little economic benefits off, focus on their main business and improve the centralization of production and operating efficiency. Meanwhile, when these projects are being constructed, enterprises in the park shall be encouraged to join in so that the public service platform is jointly structured by a number of participants.

Enhance brand building, improve the taste of the park, and build a new image. As industrial parks in China are being transformed and upgraded, it is important to develop the producer services industry, which can improve the taste of industrial parks and create new images. Therefore, the general planning of the service industry cluster park and singe project planning must be in line with the principle of high-end development as well as combination of production quality and life quality. Currently, 28-storey Industrial Promotion Center Building has been constructed, laying foundations for the high-end development of the park. Projects in the future must be characteristic and representative of warp knitting industry to further enhance the regional brand.

Integrate warp knitting industry resources and achieve the intensive development. The warp knitting service industry cluster park under planning is no more than $2 \mathrm{~km}$ from the current downtown of Haining. To construct an "enclave" service industry cluster park requires huge investments and huge work for Haining, which will be very hard. On the one hand, at the beginning, old factory buildings and old houses shall be utilized to properly reduce the cost; on the other hand, during construction, it requires innovation and distinctiveness from other industrial parks. Moreover, related authorities shall issue substantial policies, center on the coordinated development of the producer services industry and the consumer services industry inside the cluster park, increase supporting facilities, and attract service enterprises to settle in and people to work here. Thus, the comprehensive benefits of the cluster park will be achieved as early as possible.

Enhance uniformity with the new southern district concerning planning and construction. The new southern district is the core of urban development of Haining. The service industry cluster park, as a "spearhead", advances the urban expansion in the south of Haining. The construction of this industry park as the preliminary project of the new southern district will make positive externality effects, and greatly raise the land prices around the cluster park. Through surrounding development, it will speed up the construction of the new southern district and integrate into the new southern district in the future. Therefore, the planning of the cluster park must be coordinated with the overall development plan of the new southern district of Haining; a part of the producer services industry shall not only support the park, but also serve the future downtown of Haining. Spatial arrangement and construction schedule of each function area of the park, project planning/design, as well as landscape and key infrastructure planning/design shall be consistent with the determined planning requirements of the new southern district. 


\section{Acknowledgement}

This research was financially supported by the Academic Climbing Project from Education Department of Zhejiang Province with the number of pd2013324 and the Soft Science Subject of Zhejiang Province with the number of 2013C35022.

\section{References}

[1] Ramírez-Pasillas, Marcela. International trade fairs as amplifiers of permanent and temporary proximities in clusters. Entrepreneurship \& Regional Development, Mar 2010, Vol. 22 Issue 2, p155-187.

[2] Porter, M. E. Clusters and the New Economics of Competition. Harvard Business Review, 1998(Nov.-Dec.):77-90.

[3] HumPhrey J, Sehmitz H. Governance and Upgrading: Linking Industrial Cluster and Global Value Chain Research. Sussex: University of Sussex, 2000.

[4] Weber,A. English Translation: The Theory of the Location of Industries. Chicago University Press, Chicago, 1929.

[5] Hoover,E.M. Location Theory and the Shoe and Leather Industries. Harvard University Press, Cambridge, MA, 1936.

[6] Christaller,W. English Translation: The Central Places of Southern Germany.Prentice-Hall, Englewood Cliffs NJ,1966.

[7] Catherine Beadry and Perter Swann. Growth in Industrial Cluster: a Birds Eye View of the United Kingdom. SIEPR Discussion Paper, 2001, 10-38.

[8] Fujita,M.and Krugman,P. The New Economic Geography: Past, Present and the Future. Papers in Regional Science, 2004(83):139-164. 